\title{
The Effect of Systemic Venous Drainage of the Pancreas on Insulin Sensitivity in Dogs
}

\author{
J. Radziuk, ${ }^{\star}$ P. Barron, ${ }^{\star}$ H. Najm, ${ }^{\star}$ and J. Davies * \\ Departments of ${ }^{*}$ Medicine and ${ }^{\ddagger}$ Surgery, Ottawa Civic Hospital, and the University of Ottawa, Ottawa, Ontario, Canada KlY 4 E9
}

\begin{abstract}
To assess the metabolic consequences of the diversion of the pancreatic venous drainage to the systemic circulation, the pancreaticoduodenal and gastrosplenic veins were anastomosed to the inferior vena cava in nine normal dogs. This procedure maintained the integrity of the entire pancreas while shunting the hormonal output of the pancreas to the periphery. The metabolic effects were assessed from the sensitivity to insulin during a euglycemic hyperinsulinemic glucose clamp using an insulin infusion of $800 \mu \mathrm{U} / \mathrm{kg}$ per min. The studies were controlled by their duplication in seven dogs identically treated but with the pancreatic veins reanastomosed to the portal vein. No differences in systemic insulin levels or insulin sensitivity before and after surgery were seen under these circumstances. After diversion, however, basal insulin levels rose from $4.5 \pm 1.0$ to 11.5 $\pm 2.5 \mu \mathrm{U} / \mathrm{ml}$. Basal glucose metabolic clearance rate (MCR) rose to 3.0 \pm 0.4 from $2.0 \pm 0.3 \mathrm{ml} / \mathrm{kg}$ per $\mathrm{min}$. On insulin infusion, maximal stimulation of MCR within the 2-h infusion period was to $15.2 \pm 2.5 \mathrm{ml} / \mathrm{kg}$ per min preoperatively and to $7.2 \pm 0.8 \mathrm{ml} / \mathrm{kg}$ per $\mathrm{min}$ after diversion. Using ratios of MCR-to-insulin concentration as an index of insulin sensitivity, it was demonstrated that this index decreased by at least $50 \%$ after diversion. These data imply that portal venous drainage of the pancreas is an important factor in the determination of peripheral insulin sensitivity. (J. Clin. Invest. 92:1713-1721.) Key words: Diabetes $\bullet$ pancreas transplantation • insulin resistance $\bullet$ portal insulin $\bullet$ peripheral insulin
\end{abstract}

\section{Introduction}

The physiological role of the portal delivery of insulin is still incompletely understood. As a consequence, the therapeutic implications of this route of insulin administration are difficult to evaluate. The expectation might be that, during portal insulin entry, the higher levels of insulin encountered by the liver would render this organ more responsive to variations in insulin release. Studies examining this issue are divided into those that compare the effects of acute insulin administration by the two routes and those that are chronic in nature. The latter have been primarily focused in the area of pancreas transplantation since this usually entails its venous drainage into the systemic circulation.

Address correspondence to Dr. J. Radziuk, Clinical Investigation Unit, Ottawa Civic Hospital, 1053 Carling Avenue, Ottawa, ON K1Y 4E9, Canada.

Received for publication 2 September 1992 and in revised form 14 May 1993.

J. Clin. Invest.

(c) The American Society for Clinical Investigation, Inc.

$0021-9738 / 93 / 10 / 1713 / 09 \$ 2.00$

Volume 92, October 1993, 1713-1721
In the short term, during insulin infusions the liver has been found to be more sensitive to increasing insulin levels than the periphery (1-4), suggesting that it is the initial site at which glycemia may be regulated. Evidence as to relative efficiency of portal and peripheral delivery of insulin in the regulation of both glucose and other aspects of metabolism is not entirely consistent. Some studies have shown a relative superiority of portal infusion in the maintenance of normal metabolic parameters $(5,6)$, including glycemia (6) and insulinemia (5). Other work indicates that the two routes of insulin entry are essentially equivalent (7-9). Still other studies demonstrated that when an equivalent amount of insulin is administered peripherally and portally, the peripheral insulin may have a more profound effect on glycemia, perhaps because the mobilization of peripheral substrates for hepatic gluconeogensis is inhibited to a greater extent $(10,11)$.

The debate on the importance of portal insulin entry extends to the chronic situation. This is particularly pertinent to therapeutic issues since the normal route of insulin administration in the treatment of diabetes is subcutaneous and therefore peripheral. The intraperitoneal route has been suggested since a porto-systemic gradient of insulin concentrations is generated that is similar to that seen physiologically $(12,13)$. The therapeutic relevance of this gradient, however, is not yet resolved $(5-11,14)$. A decrease in hepatic insulin uptake and therefore in the porto-systemic gradient is seen in liver disease (15-17) and is associated with insulin resistance suggestive of a potential causative role for this hepatic lesion. The loss of this gradient in insulin levels is accentuated in pancreas transplantation where the venous drainage is usually peripheral. Again, the effects of bypassing the liver in this way are not completely clear.

After pancreas transplantation in humans it has been found that fasting and meal-stimulated insulin concentrations are increased (18-22) or remain near normal $(23,24)$ when compared to appropriate controls. Regardless of the circumstances, in most cases (all except reference 23), there appear to be no or minor changes in glucose tolerance, suggesting either decreases $(18,20,23)$ or minimal changes $(21,22,24,25)$ in insulin sensitivity. These observations are likely confounded by the varying circumstances in which they are made: $(a)$ the relative degree of control in the preceding diabetic state; $(b)$ the varying beta cell mass that is transplanted; $(c)$ denervation of the pancreas $(26) ;(d)$ immunosuppression; and $(e)$ the site of venous drainage of the pancreas and therefore the site of insulin delivery (24).

Recent work in a dog model using a partial pancreatectomy and systemic venous drainage of the remaining pancreas showed normal glucose tolerance with hyperinsulinemic responses (27) but with no significant changes in insulin action (28). To assess the effect of a single factor on insulin action (the strictly anatomical ramifications of chronic peripheral insulin delivery), a dog model was developed where: $(a)$ pancreatic venous drainage was diverted from the portal vein to the 
systemic circulation; $(b)$ the arterial circulation and accompanying neural input to the pancreas was maintained; $(c)$ the damage to the pancreas was minimized with the entire pancreas remaining intact; or $(d)$ portal flow was not interrupted with no liver damage resulting. In this model insulin levels were determined in the fasting state and during a euglycemic hyperinsulinemic clamp. The metabolic clearance of glucose was estimated simultaneously as a measure of insulin action. These assessments were performed both before and after surgery as well as in sham-operated animals in which portal pancreatic venous drainage was maintained.

\section{Methods}

Animals. 16 healthy adult mongrel dogs, both male and female, and in a weight range of $15-25 \mathrm{~kg}$, were used in these studies. Each animal first underwent an assessment of its insulin sensitivity as described below. 1 wk later, after an overnight fast, anesthesia was induced using 0.04 $\mathrm{mg} / \mathrm{kg}$ atropine and $1 \mathrm{ml} / 20 \mathrm{lb}$ Innovar-vet (fentanyl/doperidol) and maintained with fluothane (Ayerst, Montreal, Canada). The animals then underwent one of the surgical procedures below. After recovery from surgery the animals were fed standard chow (Canine 1600; Agway, Syracuse, NY). 2 wk after recovery the insulin sensitivity of each animal was reassessed. All protocols were approved by the Ottawa Civic Hospital Ethics Committee.

\section{Surgery}

Diversion of pancreatic venous drainage to peripheral circulation. The pancreaticoduodenal vein and the gastrosplenic vein were both transected at the portal vein and reanastomosed end-to-side to the inferior vena cava. Small venous branches between the pancreas and duodenum were ligated, except in the immediate vicinity of the pancreatic duct. The arterial circulation with its accompanying neural input to the pancreas was left intact. With the diversion of both veins to the systemic circulation no congestion or ischemia of any part of the pancreas was noted. 11 animals successfully underwent this procedure.

Sham operation: reanastomosis of pancreatic venous drainage to the portal vein. In seven animals, instead of anastomosing the pancreaticoduodenal and gastrosplenic veins to the inferior vena cava, these were reanastomosed to the portal vein. The remainder of the procedure was identical. Those animals that had undergone the same surgical procedure but whose pancreatic venous drainage was portal were used as controls for those with the diverted venous drainage.

Postoperative monitoring. Plasma levels of amylase, lipase, and urea nitrogen were measured before surgery as well as $3 \mathrm{~d}$ postoperatively. Preoperative levels were $675 \pm 83 \mathrm{U} /$ liter, $869 \pm 264 \mathrm{U} /$ liter, and $3.6 \pm 0.4 \mathrm{mg} / \mathrm{dl}$ for amylase, lipase, and urea nitrogen, respectively. After surgery these were $817 \pm 90 \mathrm{U} /$ liter, $1,129 \pm 271 \mathrm{U} /$ liter, and $3.1 \pm 0.2 \mathrm{mg} / \mathrm{dl}$, respectively (NS). Hematocrit was $36 \pm 1 \%$ before surgery and $37 \pm 1 \% 3 \mathrm{~d}$ later. The animals' weight stabilized rapidly on resumption of eating ( $2 \mathrm{~d}$ postoperatively) and was at the preoperative level for at least 1 wk before studies. They also demonstrated good general health, normal stools, and a good appetite.

Experimental procedures. 32 studies were performed in the 16 animals. Catheters used in these studies were either from Intramedic (PE tubing; Clay-Adams, Parsippany, NJ) or Tygon tubing (Norton Co., Akron, $\mathrm{OH}$ ). For the preoperative hyperinsulinemic clamp these were introduced percutaneously just before the study. Two were placed in jugular veins and one in the inferior vena cava by way of the saphenous vein. The former lines were used for the infusion of tracer and the latter for sampling. Venous lines were used for sampling so that each animal could be limited to one surgical procedure. Permanent jugular, inferior vena cava, and arterial lines were placed during the surgical procedure and were exteriorized to the back and kept in a pouch secured using Elastoplast bandages (Smith \& Nephew Inc., Lachine, Canada). A catheter was also placed in the portal vein and advanced to the porta hepatis to monitor any pancreatic venous drainage in either the diverted or sham-operated animals. Patency of the lines was maintained using daily flushing with a dilute heparin solution $(100 \mathrm{U} / \mathrm{ml})$. If arterial lines were used for sampling postoperatively, simultaneous samples were taken from the inferior vena cava periodically throughout the study to verify that glucose and label values were not significantly different at the two sampling sites. Inferior vena cava values were found to be $97 \pm 4$ and $98 \pm 3 \%$ of the arterial values for glucose and tracer, respectively.

The protocol for each study was as follows. The dog was fasted for $18-20 \mathrm{~h}$ before the study. Water was available ad libitum. At $t=-150$ min, a constant tracer infusion using a infusion pump (Harvard Apparatus, South Natick, MA) was initiated and continued throughout the experiment. At $t=0$, an insulin (porcine insulin; Eli Lilly and Co., Indianapolis, IN) infusion was started at $800 \mu \mathrm{U} / \mathrm{kg}$ per min and continued for $2 \mathrm{~h}$. Samples were taken at frequent intervals for glucose measurement using a glucose analyzer (Beckman Instruments, Inc., Fullerton, CA). Glucose (20\% dextrose; Travenol Laboratories, Toronto, Canada) was infused at variable rates using a pump (IVAC Corp., San Diego, CA) to maintain euglycemia. Blood samples for tracer and insulin levels were drawn at variable intervals (more frequently when rapid changes were expected) and collected in heparinized tubes. The blood was quantitatively replaced with saline. $\left[{ }^{3} \mathrm{H}\right] 3-$ Glucose was used in the first study and $\left[{ }^{3} \mathrm{H}\right] 6$-glucose in the second study, since tritium in the sixth position of glucose could be measured independently of the total tritiated glucose.

Evaluation of diversion of pancreatic venous drainage. The success of the surgical diversion was assessed on a separate day from the insulin clamp by comparing the portal and peripheral (inferior vena cava) levels of insulin under basal fasting conditions and during a 90-min glucose infusion at $10 \mathrm{mg} / \mathrm{kg}$ per min. Two samples were taken during the basal period followed by samples every $30 \mathrm{~min}$ during the infusion. In the case of diversions the surgery was deemed successful if the portal insulin level was lower than or equal to the simultaneous value in the inferior vena cava. Plasma glucagon levels were also measured in these samples to evaluate the extent to which levels of this hormone are affected by pancreatic venous diversion. In two cases portal catheter patency was lost and a similar procedure was followed under anesthesia before death and autopsy. Two animals from the diversion group were eliminated from the study on the basis of these criteria. The nine remaining animals were studied as indicated.

The values of the insulin and glucagon levels obtained are reported below. At autopsy, inspection revealed an intact pancreas with no gross damage and patent anastomoses in the 16 animals reported.

Analysis. All plasma samples for tracer determinations were prepared for counting by deproteinization (31). In the case of $\left[{ }^{3} \mathrm{H}\right] 3$-glucose, an aliquot of the supernatant was evaporated at $60^{\circ} \mathrm{C}$, the residue was redissolved in water and formula 989 (New England Nuclear, Boston, MA), and the radioactivity was determined in a liquid scintillation counter (Tricarb 2200CA; Canberra Packard, Dowers Grove, IL). For $\left[{ }^{3} \mathrm{H}\right] 6$-glucose, the supernatant after deproteinization was further passed through an ion exchange resin (Dowex 1-X8; Bio-Rad Laboratories, Richmond, CA) to remove acid components. Radioactivity in the sixth position of glucose was determined by dimedone precipitation of the formaldehyde formed after periodate oxidation of glucose (29). All tracers (New England Nuclear) were repurified chromatographically in our laboratory on an HPX-87C column (Bio-Rad Laboratories) using a single pump system (Shimadzu, Kyoto, Japan ). Plasma immunoreactive insulin levels were determined as previously described (30) using the antibody obtained from Dr. P. Wright, University of Indiana. Plasma immunoreactive glucagon was measured using the pancreaticspecific antibody from Linco (St. Louis, MO).

\section{Calculations}

Measurements of glucose flux. Glucose and tracer data were smoothed using a set of polynomials as previously described (31). A two-compartment model with glucose removal, $\left(R_{d}\right)$, in the first or sampled compartment (31) was used to calculate this removal and the meta- 


\begin{tabular}{|c|c|c|c|c|c|}
\hline & & Basal & $30 \mathrm{~min}$ & $60 \mathrm{~min}$ & $90 \mathrm{~min}$ \\
\hline \multicolumn{6}{|l|}{ Diversion } \\
\hline \multirow[t]{2}{*}{ Insulin* } & IVC & $11.4 \pm 1.5$ & $72 \pm 21$ & $68 \pm 20$ & $78 \pm 23$ \\
\hline & Portal & $12.0 \pm 2.0$ & $67 \pm 18$ & $59 \pm 15$ & $50 \pm 10$ \\
\hline \multirow[t]{2}{*}{ Glucagon ${ }^{\ddagger}$} & IVC & $161 \pm 20$ & $152 \pm 29$ & $148 \pm 28$ & $132 \pm 30$ \\
\hline & Portal & $170 \pm 16$ & $154 \pm 22$ & $142 \pm 24$ & $145 \pm 25$ \\
\hline \multicolumn{6}{|c|}{ Sham operation } \\
\hline \multirow[t]{2}{*}{ Insulin } & IVC & $4.5 \pm 1.0$ & $39 \pm 11$ & $36 \pm 11$ & $38 \pm 10$ \\
\hline & Portal & $16.7 \pm 3.6$ & $78 \pm 31$ & $86 \pm 20$ & $109 \pm 38$ \\
\hline \multirow[t]{2}{*}{ Glucagon } & IVC & $101 \pm 3$ & $104 \pm 11$ & $108 \pm 11$ & $87 \pm 10$ \\
\hline & Portal & $133 \pm 7$ & $98 \pm 14$ & $10 \pm 14$ & $86 \pm 11$ \\
\hline
\end{tabular}

Glucose was infused at $10 \mathrm{mg} / \mathrm{kg}$ per min for $90 \mathrm{~min}$ after the basal samples were taken. $\quad{ }^{*}$ Insulin concentrations are in $\mu \mathrm{U} / \mathrm{ml}$. ${ }^{\ddagger} \mathrm{Glucagon}$ concentrations are in $\mathrm{pg} / \mathrm{ml}$.

bolic clearance was determined by dividing this by the plasma glucose concentration. The formulae used are presented in detail ( 32$)$.

Measures of insulin sensitivity. A 2-h infusion of insulin was administered in these studies for the assessment insulin sensitivity (e.g., reference 21 ). The metabolic clearance rate $(\mathrm{MCR})^{1}$ of glucose was calculated as above. This parameter was used for the assessment of systemic insulin sensitivity since it is less dependent on glucose than $\left(R_{d}\right)$, although this is not an issue during euglycemic clamps. Since the MCR did not reach a steady value by the end of the insulin infusion, the MCR (maximal) reached at the end of the study was used as a minimal estimate of its equilibrium value. One index of insulin sensitivity would then be the ratio of the final MCR reached and the insulin value. A second estimate was made by extrapolating the MCR to steady-state using a model that relates MCR to insulin concentrations in a remote compartment (33-36):

$\frac{d M}{d t}=-a_{1} M+a_{2} i$,

where $M$ is the MCR of insulin and $i$ is its plasma insulin concentration, and $a_{1}$ and $a_{2}$ are constants. Since $i$ is essentially constant after 10 min of insulin infusion, MCR as a function of time can be approximated as:

$M=A\left(1-e^{-a_{1} t}\right)$,

where $A$ is a constant. For each study, the calculated MCR values were fitted to the above function using a nonlinear least squares approach. The equilibrium value was then estimated as $A$. The second estimate of insulin sensitivity used was therefore $\Delta M / \Delta i$, where $\Delta M$ is the increment of the (extrapolated) value of $M$ from basal and $\Delta i$ is the equivalent increment in insulin.

Statistical analysis. Comparisons were made for data before surgery and after surgery for both the case of diversion and sham operation. In addition, the sham and diverted groups were compared with each other both before and after surgery. Preliminary analysis was performed using a $2 \times 2$-factor analysis of variance (ANOVA) with multiple comparison tests. When a significant interaction term indicated a difference between shams and diversions in the main effect (between pre- and postoperative), a one-way ANOVA was used to further compare the groups above using a two-factorial design with time as a repeated measure (37). To determine where curves start to differ significantly, $t$ tests were performed post-hoc at every time point for the greatest differences of the mean (38). Significance was assumed if $P<0.05$.

1. Abbreviation used in this paper: MCR, metabolic clearance rate.

\section{Results}

Evaluation of diversion. As seen from Table I, insulin levels were higher $(P<0.05)$ both in the inferior vena cava and the portal vein after diversion of pancreatic venous drainage compared with inferior vena cava levels after sham operation. Portal levels were higher than those in the inferior vena cava after sham operation but not after diversion. As stated in Methods, this criterion was also used in individual cases to assess the success of the diversion when this was implemented.

Inspection of the concentrations of glucagon reveals a portal-peripheral gradient arising from glucagon secretion into the portal vein only under basal conditions in the sham-operated animals $(P<0.05)$. The gradient is obliterated in diverted animals and is also no longer seen during glucose infusion. In both cases there is a slow decrease in concentrations as the infusion progresses. Interestingly, peripheral glucagon levels are increased $(P<0.05)$ by $\sim 50 \%$ after diversion.

Measures of insulin sensitivity. The results of these studies are shown in Figs. 1 and 2. Basal fasting glycemia was identical $(P>0.5)$ in the animals preoperatively $(93 \pm 92$ and $94 \pm 1 \mathrm{mg} /$ $\mathrm{dl})$, in those with diverted pancreatic venous drainage $(93 \pm 2$ $\mathrm{mg} / \mathrm{dl}$ ), and the shams who underwent reanastomosis of the pancreatic venous drainage to the portal vein $(95 \pm 2 \mathrm{mg} / \mathrm{dl})$. Basal plasma lactate levels were also not significantly different $(587 \pm 52$ and $758 \pm 74 \mathrm{nmol} / \mathrm{ml}$ in the preoperative cases and $787 \pm 150$ and $683 \pm 121 \mathrm{nmol} / \mathrm{ml}$ for the diversion $[P>0.1]$ and sham [ $P>0.1]$ operation, respectively), although more variation was present.

Basal plasma insulin levels, on the other hand, rose significantly $(P<0.05)$ after diversion: from $4.5 \pm 1.0$ to $11.5 \pm 2.5$ $\mu \mathrm{U} / \mathrm{ml}$. For the shams, the levels were $5.1 \pm 1.2 \mu \mathrm{U} / \mathrm{ml}$ before and $5.7 \pm 1.8 \mu \mathrm{U} / \mathrm{ml}$ after surgery (NS). The basal MCR of glucose was $2.0 \pm 0.3$ and $2.6 \pm 0.4 \mathrm{ml} / \mathrm{kg}$ per min before diversion and sham operation, respectively, $3.0 \pm 0.4 \mathrm{ml} / \mathrm{kg}$ per min after diversion $(P<0.05$ vs. preoperative $)$, and $2.7 \pm 0.4 \mathrm{ml} / \mathrm{kg}$ per min (NS) in sham-operated dogs.

During the 2-h insulin infusion both the glucose and lactate levels were identical pre- and postoperatively in all groups (Fig. 1). Insulin concentrations during the infusion were $33 \pm 4 \mu \mathrm{U} /$ $\mathrm{ml}$ before diversion and sham operation, respectively, 37 \pm 5 $\mu \mathrm{U} / \mathrm{ml}$ after diversion (NS), and $30 \pm 5 \mu \mathrm{U} / \mathrm{ml}$ after sham surgery (NS). The MCR rose from basal to $15.2 \pm 2.5$ and 

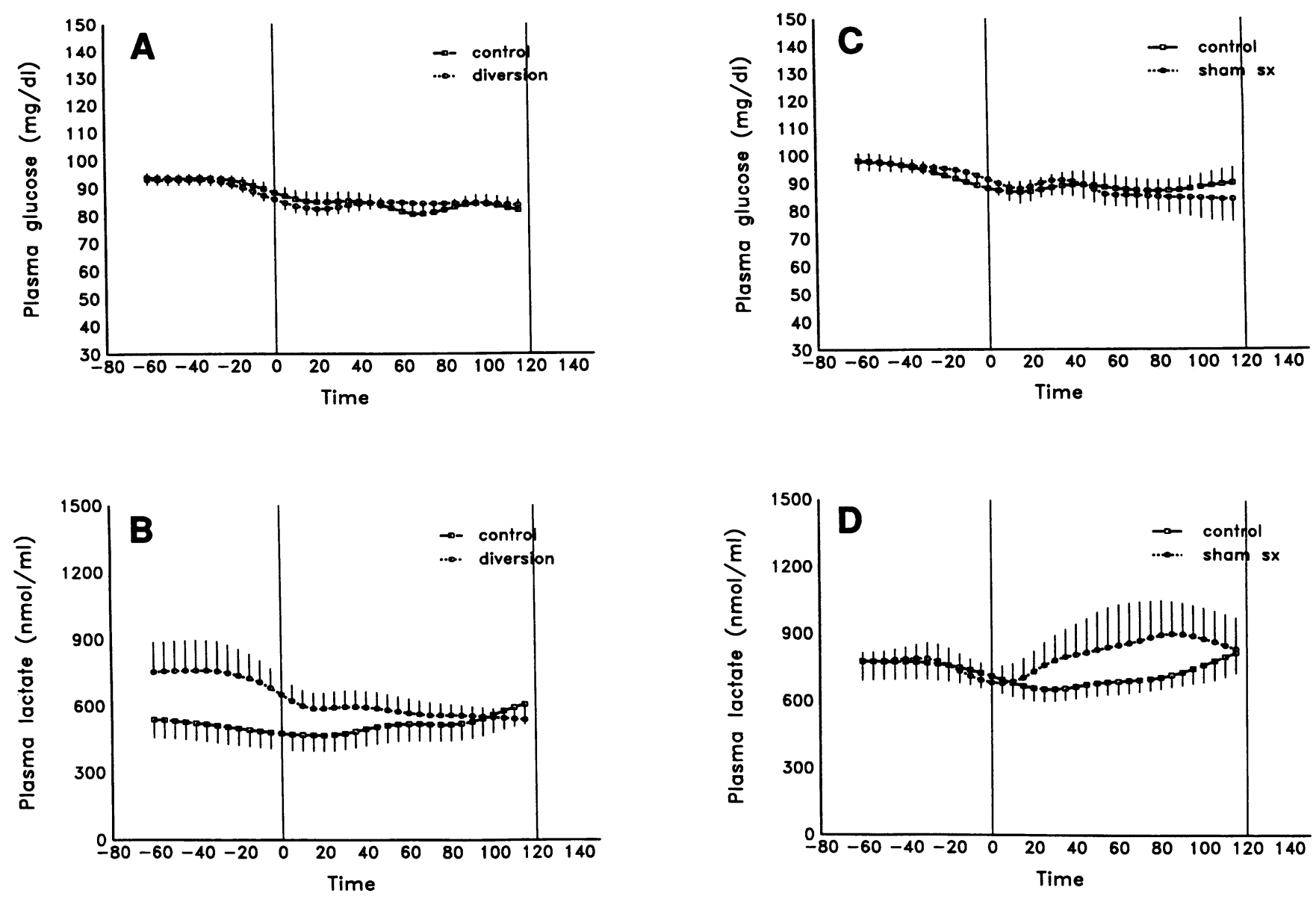

Figure 1. $(A$ and $B)$ Diversion of pancreatic venous drainage. Glucose and lactate levels under basal conditions and during the infusion of somatostatin $(0.5 \mu \mathrm{g} / \mathrm{kg}$ per $\mathrm{min})$ and insulin $(800 \mu \mathrm{U} / \mathrm{kg}$ per min $)$ from 0 to $120 \mathrm{~min}$. Identical levels of glycemia and plasma lactate are maintained throughout the study. ( $C$ and $D$ ) Sham surgery with reanastomosis of venous drainage to portal vein. The glucose and lactate levels are not significantly different before and during insulin infusion.

$11.8 \pm 1.3 \mathrm{ml} / \mathrm{kg}$ per min in the preoperative animals (7.6-fold increase) and to $7.2 \pm 0.8 \mathrm{ml} / \mathrm{kg}$ per min after diversion (2.4fold increase). After sham surgery, MCR increased to $11.2 \pm 2.5$ $\mathrm{ml} / \mathrm{kg}$ per min.

In the animals that underwent diversion of their pancreatic venous drainage, MCR was higher after diversion compared with preoperatively $(P<0.05)$. No such change was seen after sham surgery. MCR during the insulin changes was, however, also higher postoperatively in the shams than in the diverted animals $(P<0.05)$. In diverted animals the MCR diverged from preoperative values after $t=30 \mathrm{~min}(P<0.05)$. Table II summarizes the quantitative estimates of insulin sensitivity obtained from these data. There is a two- to threefold drop in insulin sensitivity between the preoperative estimates and those after diversion. Simultaneously, there is no significant change after the sham operation. Although insulin sensitivity was not as high in the latter group, a twofold difference persisted between the diverted and sham-operated groups.

The time course of the rate of glucose appearance $\left(R_{a}\right)$ calculated in these studies reflects that in MCR since glucose levels were clamped. Table III provides a summary of the integrated value of $R_{a}$ and the total amount of glucose infused exogenously during the study. In the case of the sham-operated animals, total $R_{a}$ is somewhat lower since glycemia was de- creased in the last hour of the clamp. Interestingly, basal glucose production increased after the diversion $(P<0.05)$. During the hyperinsulinemic clamp there is no difference in the mean endogenous glucose production rate, which is suppressed $30-40 \%$ relative to basal.

\section{Discussion}

The implications of the data presented here are both physiological and therapeutic. They provide a basis for the portal venous drainage of the pancreas in so far as peripheral drainage induced insulin resistance. The same consideration could apply to therapeutic reasoning on the optimality of the route of insulin entry. Most pertinent to the present observations is the site of pancreas transplantation. No consensus appears to have been reached in this regard although the data given here suggest that when the transplant is peripheral, insulin resistance will be induced.

Methodology. The conclusions reached are dependent on: (a) experimental techniques that do not induce insulin resistance due to surgical stress or pancreatic damage, and $(b)$ correct tracer methodology.

The animals appeared healthy with normal appetite and stable weight postoperatively. Serum amylases returned to nor- 

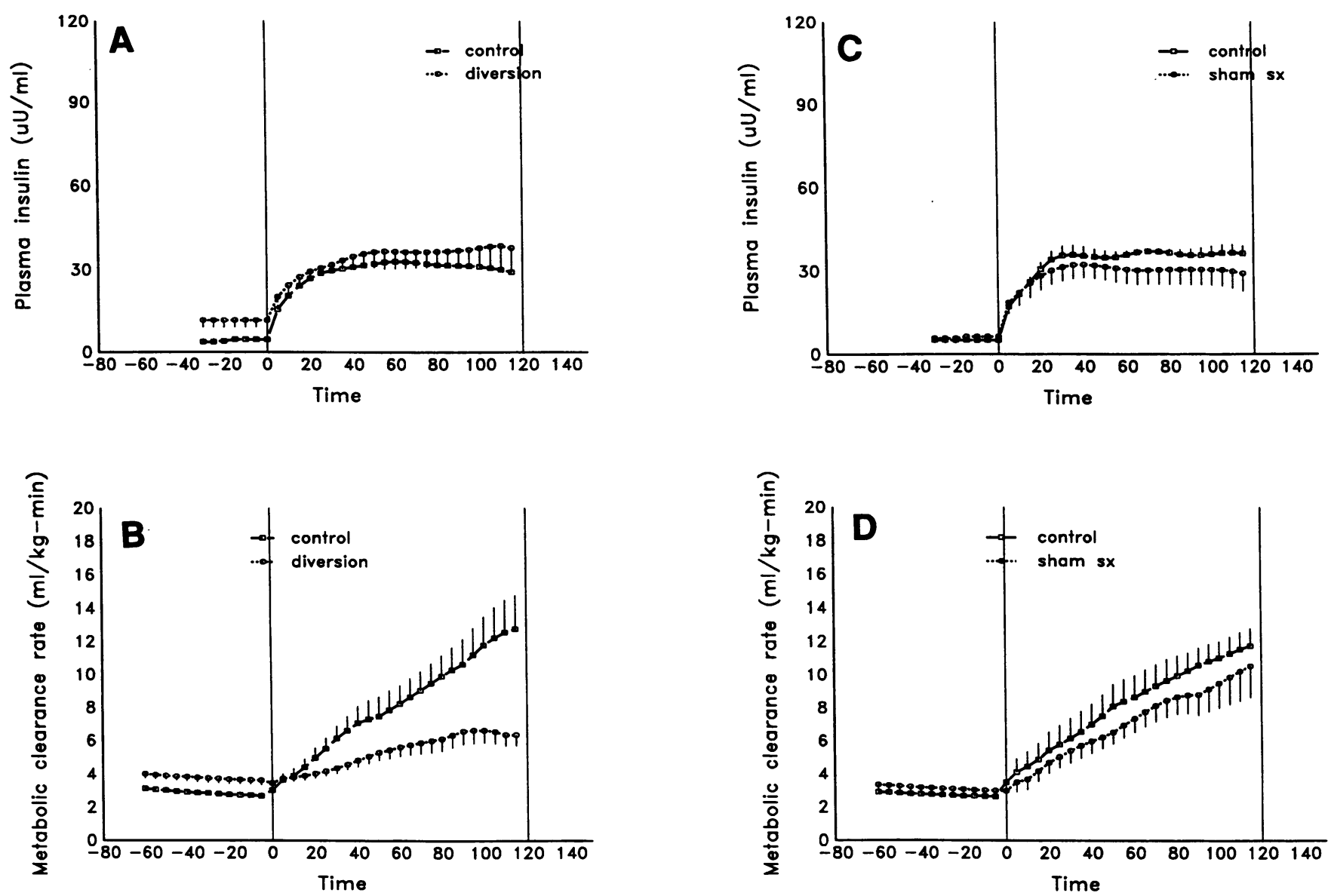

Figure 2. $(A$ and $B$ ) Diversion of pancreatic venous drainage. Basal insulin levels are increased whereas somatostatin and insulin ( $800 \mu \mathrm{U} / \mathrm{kg}$ per $\min$ ) infusion increases levels of insulin to $\sim 40 \mu \mathrm{U} / \mathrm{ml}$ both before and after surgery $(A)$. The metabolic clearance of glucose, on the other hand, rises twice as quickly after surgery compared with preoperatively, indicating a decrease in insulin sensitivity after diversion $(B)$. $(C$ and $D$ ) Insulin levels and changes in glucose MCR are not significantly different after sham surgery where pancreatic veins are reanastomosed to the portal vein.

mal levels within $2 \mathrm{~d}$ of surgery and all other biochemical and hematological parameters were normal at the time of the postsurgical studies. Functional impairment could arise from the surgery, particularly from partially occluding the venous drain- age from the pancreas during the transection and anastomosis of each of the two veins that are diverted, and from the ligation of the smaller venous tributaries that drain into the duodenal circulation. The major evidence that this did not occur is that

Table II. Indices of Insulin Sensitivity

\begin{tabular}{cccccc}
\multicolumn{2}{c}{ Diversion } & & \multicolumn{2}{c}{ Sham } \\
\cline { 4 - 5 } $\begin{array}{c}\text { Preoperative } \\
\text { (1) }\end{array}$ & $\begin{array}{c}\text { Postoperative } \\
\text { (2) }\end{array}$ & & $\begin{array}{c}\text { Preoperative } \\
\text { (3) }\end{array}$ & $\begin{array}{c}\text { Postoperative } \\
\text { (4) }\end{array}$
\end{tabular}

Insulin concentration $(\mu \mathrm{U} / \mathrm{ml})$

Basal

Infusion

MCR (ml/kg per min)

Basal

Insulin infusion (maximum)

Insulin infusion (extrapolated, $\Delta$ )

Index of insulin sensitivity

Max MCR/insulin concentration

$\triangle$ Extrapolated MCR/ $\Delta$ insulin

$4.5 \pm 1.0$
$33 \pm 4$

$2.0 \pm 0.3$
$15.2 \pm 2.5$
$14.7 \pm 2.7$
$0.51 \pm 0.08$
$0.63 \pm 0.15$

$11.5 \pm 2.5^{*}$

$36 \pm 3$

$3.0 \pm 0.4^{\ddagger}$

$7.2 \pm 0.8^{*}$

$3.5 \pm 0.7^{*}$

$0.22 \pm 0.03^{*}$

$0.19 \pm 0.06^{*}$
$5.7 \pm 1.8$

$37 \pm 5$

$30 \pm 5$

$2.6 \pm 0.4$

$13.7 \pm 1.3$

$12.9 \pm 0.9$

$2.7 \pm 0.4$

$13.1 \pm 2.1$

$11.3 \pm 2.7$

$0.39 \pm 0.04$

$0.43 \pm 0.06$

$0.49 \pm 0.06$

$0.53 \pm 0.10$

${ }^{*}$ Different from columns 1,3 , and $4(P<0.05) .{ }^{\ddagger}$ Different from column $1(P<0.05)$. 
the sham-operated animals, where the interventions were identical to those in the "diverted" animals, demonstrated a response in glucose MCR to insulin that was the same as their own preoperative response and as the preoperative response in all animals taken together.

Tracer methods. Glucose flux rates and, in particular, its metabolic clearance rate were calculated from data based on a constant, unprimed tracer infusion and a two-compartment model for glucose kinetics (31). Specific activity clamping was not used since it is only necessary to compensate for errors in model structure when a single-compartment model is used in the face of rapid changes in flux rates and therefore tracer concentrations. This has been demonstrated theoretically $(39,40)$. In addition, the original validation of the two-compartment model was done in the face of large excursions in glucose concentrations and rapid increases in MCR (similar to those seen after a step increase in insulinemia). Finally, it is useful to point out that major differences between approaches occur when the rate of change of tracer concentrations is highest and is usually only detectable in the calculation of endogenous glucose production in the face of a large exogenous input. Since these changes are most rapid in the first hour after the initiation of insulin infusion, the argument is less relevant in the latter part of the study. Confirmatory of this, suppression of endogenous glucose production is estimated at between 30 and $40 \%$ (Table III), consistent with previous estimates at these insulin levels and $<100 \%$, a situation that can occur when inappropriate models are used (40). When a model of appropriate order and structure is used, therefore, the calculation is valid as has previously been demonstrated under similar (31) conditions.

Assessment of insulin sensitivity. In these studies insulin sensitivity is calculated based on the metabolic clearance rate of glucose. In the context of euglycemic clamps, this is different from the rate of glucose utilization $\left(R_{d}\right)$ only by a constant factor (the glucose concentration). The MCR in preoperative or sham dogs is significantly different from that after diversion. The MCR of glucose is therefore unequivocally decreased when insulin enters directly into the systemic circulation. Since MCR did not always reach equilibrium at $2 \mathrm{~h}$ after initiation of insulin infusion, a first approximation of insulin sensitivity

Table III. Integrated Glucose Production and Infusion and Mean Endogenous Glucose Formation during the Hyperinsulinemic Clamp

\begin{tabular}{llll}
\hline & Preoperative & Diversion & Sham \\
\hline $\begin{array}{l}\text { Total } \mathrm{R}_{\mathrm{a}} \text { during insulin infusion } \\
(\mathrm{mg} / \mathrm{kg})\end{array}$ & & & \\
Total glucose infused $(\mathrm{mg} / \mathrm{kg})$ & $643 \pm 113$ & $517 \pm 59^{*}$ & $710 \pm 85$ \\
$\begin{array}{l}\text { Difference } \\
\text { Mean endogenous glucose production } \\
\quad(\mathrm{mg} / \mathrm{kg} \text { per min) }\end{array}$ & $145 \pm 22$ & $186 \pm 33$ & $201 \pm 39$ \\
$\begin{array}{l}\text { Mean basal (preinfusion) glucose } \\
\text { production (mg/kg per min) }\end{array}$ & $1.3 \pm 0.2$ & $1.6 \pm 0.3$ & $1.7 \pm 0.3$ \\
$\begin{array}{l}\text { Percent suppression } \\
\text { Pron }\end{array}$ & $2.0 \pm 0.3$ & $2.8 \pm 0.4^{\ddagger}$ & $2.7 \pm 0.6$ \\
& $35 \pm 5$ & $42 \pm 5$ & $37 \pm 11$ \\
\hline
\end{tabular}

* Different from preoperative group and from sham-operated animals $(P<0.05)$. $\quad{ }^{\ddagger}$ Different from preoperative group. could be obtained by dividing the final value of MCR reached by the insulin concentration. A more exact estimate can be obtained by using equations 1 and 2 . These equations describe insulin action using a "minimal" number of parameters and were derived and validated in the context of a hyperinsulinemic clamp (33-35). They have also been applied in the estimation of insulin sensitivity in the analysis of an intravenous glucose tolerance test (36), a completely nonsteady-state situation. The information content of the MCR measurements used in these studies is therefore the same as in a steady-state experiment and the extrapolations are as valid as this widely used model. It should, moreover, be pointed out that the extrapolation of the MCR to steady state corresponds to the area under the MCR curve (equation 2) throughout the experimental situation studied. This area is clearly smaller after diversion compared with the preoperative or sham-operated situations.

Insulin sensitivity after systemic venous drainage of the pancreas. The overall effect of the diversion of pancreatic venous drainage to the periphery is a significant decrease in sensitivity, as can be seen from Fig. 2 and Table II. Depending on the measure of insulin sensitivity used, this fall is 2.5-3-fold relative to the preoperative determination and 2-2.5-fold relative to sham-operated animals. It should be noted that MCR is near maximal $2 \mathrm{~h}$ after initiation of insulin infusion (e.g., reference 28 ), and therefore the estimate based on the final value is near correct. This is corroborated by the more exact determination using extrapolated values of MCR.

In summary, all estimates of insulin sensitivity indicate a fall in this parameter of $>50 \%$ after diversion of the pancreatic venous drainage to the systemic circulation. This change in sensitivity is primarily peripheral since no major differences are seen in the effects of insulin on hepatic glucose production.

Pancreas transplantation and systemic venous drainage of the pancreas. The pancreas, and in particular the beta cell, can drain into the systemic circulation under a number of circumstances: $(a)$ porta-caval shunts, $(b)$ pancreatic transplantation, and $(c)$ specific surgical transposition of the venous drainage. These situations can occur clinically or experimentally. Portacaval shunt procedures have been performed experimentally in dogs. They generally demonstrated fasting and stimulated hyperinsulinemia $(41,42)$. Effects on glucose tolerance were less certain, probably because of varying degrees of liver damage induced by the decrease in perfusion with portal shunting.

In humans, observations on the effects of pancreas transplantation on insulin action are not completely consistent. It has generally $(18,20,22,24,43,44)$ but not always $(23)$ been demonstrated that glucose tolerance is normal, or nearly so. The mechanisms by which this is achieved are less clear and have generally been studied by comparing pancreas/kidney transplantation in diabetic patients with kidney transplants in nondiabetic subjects or with immunosuppressive therapy alone. Nauck et al. (24) showed a decrease in insulin secretion compensating for its systemic entry. Wilczek et al. (22) saw comparable responses in glucose, insulin, and hepatic glucose metabolism in diabetic patients with kidney/pancreas transplants or nondiabetic subjects with kidney transplants alone. These two trials therefore do not demonstrate insulin resistance.

Other work $(18,20,44)$ also shows normal tolerance to meals but, in contrast to the previous studies, this is accompanied by hyperinsulinemia. The latter observations imply that 
insulin resistance is induced by the diversion of newly secreted insulin from the portal to the peripheral circulation. In fact, Rosenlof et al. (43) showed directly that glucose profiles are similar with portal and peripheral transplants but with a much higher insulin concentration in the latter. Christiansen et al. (23) also demonstrated peripheral insulin resistance relative to kidney transplants alone but with comparable insulin levels and glucose intolerance. After transplantation, a spectrum of metabolic outcomes is seen compared with appropriate controls, from normal glucose tolerance and insulin sensitivity, through a maintenance of glucose tolerance but with the induction of hyperinsulinemia and insulin resistance, to glucose intolerance.

To assess insulin sensitivity more carefully therefore, two approaches were taken. After pancreas transplantations insulin sensitivity was estimated directly using hyperinsulinemic euglycemic clamps and animal models were developed where aspects of the transplantation procedure could be studied more selectively.

During clamp studies, no decrease in sensitivity was seen in patients with pancreas transplantation relative to patients on comparable immunosuppressive therapy alone (20). The effect of the site of drainage was assessed in dog models that entailed partial pancreatectomy and the transposition of the venous drainage of the remnant to the peripheral circulation $(25,27,28)$. Although normal glucose tolerance with hyperinsulinemia suggesting insulin resistance (27) was seen, no significant changes in insulin sensitivity were seen in animals with portal drainage of the pancreas relative to those with peripheral drainage $(25,28)$.

It may be noteworthy that in the above studies, partial pancreatectomies of various degrees were included, perhaps obscuring the effect of the site of drainage alone. It has been suggested that a decrease in beta cell mass induced by pancreatic resection (45) or small doses of neonatal streptozotocin (46), and the resulting mild functional insulin deficiency, have effects on insulin sensitivity. In the studies presented here, the pancreas was maintained intact during the procedure with the transposition of both the gastroduodenal and splenic veins to the inferior vena cava. In this setting a marked decrease in insulin sensitivity of at least $50 \%$ was seen after diversion of venous drainage. Since there is some variation in groups of animals ( Table III), it was also important to perform comparisons pre- and postoperatively as well as to sham-operated animals. Finally, it cannot in these (or other analogous) studies be claimed that the anastomoses made constitute the only drainage of the pancreas, although this is ensured as much as possible. Any remaining portal drainage, however, works against the hypothesis, suggesting that the changes observed are a minimal estimate.

When the site of venous drainage of the pancreas was the only factor altered in the experimental model, unequivocal insulin resistance resulted. This occurred in a relatively short period of time ( $2 \mathrm{wk}$ ). Although not directly comparable with previous studies, as discussed, it does not appear to be consistent with the direct determinations of insulin sensitivity using insulin clamps. It is, however, consistent with a number of studies that have demonstrated normal glucose tolerance coupled with hyperinsulinemia both in the partially pancreatectomized dog model (27) as well as in human pancreas transplants $(18,20,44)$.
Implications in glucoregulation. The liver removes a large fraction, at least 50\%, of the insulin that impinges upon it (47), as well as a somewhat lesser fraction of glucagon (48). This implies that the diversion of the pancreatic venous drainage to the systemic circulation will at least double the amount of insulin entering the periphery in response to a similar metabolic stimulus. This results in a hyperinsulinemia and hyperglucagonemia, as demonstrated in a number of the studies discussed as well as the present one. It appears therefore that the high insulin levels will in themselves cause significant insulin resistance consistent with previous reports (e.g. reference 49). This decrease in sensitivity is primarily peripheral since the MCR of glucose primarily reflects extrahepatic glucose removal. Interestingly, although Table I was meant to provide evidence of peripheral venous drainage of the pancreas after diversion, it demonstrates that peripheral and portal insulin levels after diversion are closer to portal levels in the sham-operated animals. Similarly (under basal or preexperimental conditions), circulating glucagon after diversion is slightly higher than portal levels in the sham-operated animals. This "compensation" may account for the regulation of glucose production, which is comparable to normal or sham-operated animals (Table III and reference 22). An additional factor in this compensation might be the effect of higher peripheral insulin levels on the suppression of peripheral substrate mobilization (11). In conclusion, suppression of glucose production by the increments in insulin levels generated did not vary significantly between groups, suggesting that in the stimulated state, a decrease in glucose synthesis and a possible decrease in substrate availability combine to provide similar effects on net glucose production in all groups.

Implications in therapy. The debate as to the relative effectiveness, of portal vs. peripheral insulin in the treatment of diabetes, is ongoing (3-11). The generation of a portal-peripheral gradient implies the administration of insulin intraperitoneally (12-14), which is more complex and more invasive than the subcutaneous route. Similarly, pancreas transplants are traditionally done with peripheral venous drainage (15). The spectrum of results discussed above suggests that in different clinical situations various factors such as decreasing beta cell mass, immunosuppression protocols, as well as the site of venous drainage combine to yield varying levels of insulinemia as well as degrees of glucose tolerance. In these studies we therefore studied the site of venous drainage of the pancreas as a factor in isolation from other influences. Both peripheral hyperinsulinemia and a marked degree of insulin resistance resulted. In light of the recent emphasis on the role that these may play in the development of complications such as cardiovascular disease or hypertension $(50,51)$, these data suggest that portal venous drainage of the transplanted pancreas be a consideration in future therapeutic efforts.

Summary. In these studies, all variables potentially inherent in insulin action were maintained intact except for the physical transposition of the pancreatic venous drainage from the portal to the peripheral circulations. This intervention induced peripheral hyperinsulinemia and a decrease in sensitivity to insulin, during euglycemic hyperinsulinemic clamping, of at least $50 \%$. These data therefore imply that, at least for the transplanted pancreas, the physiological route of insulin entry is important in the generation of a normal glucoregulatory response. 


\section{Acknowledgements}

The contributions of K. Greenwood, K. Ferguson, L. Welsh, and S. Pye are gratefully acknowledged. We would also like to thank $M$. Chen and J. Pan for their assistance with the statistical analysis and D. Jones and $\mathrm{N}$. Green for their expert typing of the manuscript.

This work was supported by a grant from the Canadian Diabetes Association.

\section{References}

1. Rizza, R. A., L. J. Mandarino, and J. E. Gerich. 1981. Dose-response characteristics for effects of insulin on production and utilization of glucose in man. Am. J. Physiol. 240(Endocrinol. Metab. 3):E630-E639.

2. Kolterman, O. G., J. A. Scarlett, and J. M. Olefsky. 1982. Insulin resistance in non-insulin-dependent, type II diabetes mellitus. Clin. Endocrinol. Metab. 11:363-388.

3. Nankervis, A., J. Proietto, P. Aitken, M. Harewood, and F. Alford. 1982 Differential effects of insulin therapy on hepatic and peripheral insulin sensitivity in type 2 (non-insulin-dependent) diabetes. Diabetologia. 23:320-325.

4. Ishida, T., Z. Chap, J. Chou, R. M. Lewis, C. J. Hartley, M. L. Entman, and J. B. Field. 1984. Effects of portal and peripheral venous insulin infusion on glucose production and utilization in depancreatized, conscious dogs. Diabetes. 33:984-90.

5. Goriya, Y., A. Bahoric, E. B. Marliss, B. Zinman, and A. M. Albisser. 1981 The metabolic and hormonal responses to a mixed meal in unrestrained pancreatectomized dogs chronically treated by portal or peripheral insulin infusion. Diabetologia. 21:58-64.

6. Stevenson, R. W., J. A. Parsons, and K. G. M. M. Alberti. 1981. Comparison of the metabolic responses to portal and peripheral infusions of insulin in diabetic dogs. Metabolism. 30:745-752.

7. Botz, C. K., B. S. Leibel, W. Zingg, R. E. Gander, and A. M. Albisser. 1976 Comparison of peripheral and portal routes of insulin infusion by a computercontrolled insulin infusion system (artificial endocrine pancreas). Diabetes. 25:691-700

8. Fischer, U., R. A. Rizza, L. D. Hall, R. E. Westland, M. W. Haymond, A. H. Clemens, J. E. Gerich, and F. J. Service. 1982. Comparison of peripheral and portal venous insulin administration on postprandial metabolic responses in alloxan-diabetic dogs. Effects of identical preprogrammed complex insulin infusion waveforms. Diabetes. 31:579-584.

9. Kruszynska, Y. T., P. D. Home, L. Agius, and K. G. M. M. Alberti. 1986 Hepatic glycogen metabolism and insulin receptor status after long-term peripheral insulin delivery in the islet-transplanted diabetic rat. Diabetes. 35:306-10.

10. Freyse, E.-J., U. Fischer, G. Albrecht, S. Marx, and H. Keilacker. 1987 The effect of prehepatic insulin administration on alanine flux rates in diabetic dogs. Diabetologia. 30:402-408.

11. Ader, M., and R. N. Bergman. 1990. Peripheral effects of insulin dominate suppression of fasting hepatic glucose production. Am. J. Physiol. 258:E1020E1032.

12. Schade, D. S., R. P. Eaton, T. Davis, F. Akiya, E. Phinney, R. Kubica, E. A. Vaughan, and P. W. Day. 1981. The kinetics of peritoneal insulin absorption. Metabolism. 30:149-155.

13. Nelson, J. A., R. Stephen, S. T. Landau, D. E. Wilson, and F. H. Tyler. 1982. Intraperitoneal insulin administration produces a positive portal-systemic blood insulin gradient in unanesthetized, unrestrained swine. Metabolism. 31:969-972.

14. Jimenez, J. T., S. Walford, P. D. Home, I. Hanning, and K. G. M. M. Alberti. 1985. Free insulin levels and metabolic effects of meal-time bolus and square-wave intraperitoneal insulin infusion in insulin-dependent diabetic patients. Diabetologia. 28:728-733.

15. Marchesini, G., M. Zoli, C. Dondi, A. Angiolini, G. Forlani, A. Melli, F. B. Bianchi, and E. Pisi. 1982. Blood glucose and glucoregulatory hormones in liver cirrhosis: a study of 24 hour profiles and of the role of portal-systemic shunting. Gastroenterol. Clin. Biol. 6:272-278.

16. Petrides, A. S., and R. A. DeFronzo. 1989. Glucose and insulin metabolism in cirrhosis. J. Hepatol. (Amst.). 8:107-114.

17. Kruszynska, Y. T., P. D. Home, and N. McIntyre. 1991. Relationship between insulin sensitivity, insulin secretion and glucose tolerance in cirrhosis. Hepatology. 14:103-111.

18. Elahi, D., B. A. Clark, M. McAloon-Dyke, G. Wong, R. Brown, M. Shapiro, K. L. Minaker, T. L. Flanagan, T. Pruett, R. Gingerich, J. Hanks, and D. K. Andersen. 1991. Islet cell responses to glucose in human transplanted pancreas. Am. J. Physiol. 261:E800-E808.
19. Osei, K., D. A. Cottrell, M. L. Henry, R. J. Tesi, R. M. Ferguson, and T. M. O'Dorisio. 1992. Insulin insensitivity and glucose effectiveness in type I diabetic allograft recipients. Transplant. Proc. 24:828-830.

20. Katz, H., M. Holman, J. Velosa, P. Robertson, and R. Rizza. 1991. Effects of pancreas transplantation on postprandial glucose metabolism. N. Engl. J. Med. 325:1278-83.

21. Luzi, L., A. Secchi, F. Facchini, A. Battezzati, C. Standacher, D. Spotti, R. Castoldi, G. Ferrari, V. DiCarlo, and G. Pozza. 1990. Reduction of insulin resistance by combined kidney-pancreas transplantation in type 1 (insulin-dependent) diabetic patients. Diabetologia. 33:549-556.

22. Wilczek, H., R. Gunnarsson, P. Felig, J. Östman, C-G. Groth, and J. Wahren. 1991. Normalization of hepatic glucose regulation despite systemic insulin delivery. Studies in patients with pancreatic transplantation for type 1 (insulin-dependent) diabetes mellitus. Diabetologia. 34:345-349.

23. Christiansen, E., H. B. Andersen, K. Rasmussen, N. J. Christensen, K. Olgaard, P. Kirkegaard, B. Tronier, A. Völund, P. Damsbo, F. Burcharth, and S. Madsbad. 1993. Pancreatic beta-cell function and glucose metabolism in human segmental pancreas and kidney transplantation. Am. J. Physiol. 264:E441-E449.

24. Nauck, M., M. Büsing, E. G. Siegel, J. Talartschik, A. Baartz, T. Baartz, U. T. Hopt, H. D. Becker, and W. Creutzfeldt. 1991. Consequences of systemic venous drainage and denervation of heterotopic pancreatic transplants for insulin/C-peptide profiles in the basal state and after oral glucose. Diabetologia. 34(Suppl. 1):S81-S85.

25. Krusch, D. A., K. B. Brown, G. Cornett, A. E. Freedlender, D. L. Kaiser, and J. B. Hanks. 1989. Insulin-dependent and insulin-independent effects after surgical alterations of the pancreas. Surgery (St. Louis). 106:60-68.

26. Elahi, D., M. McAloon-Dyke, B. A. Clark, B. B. Kahn, J. E. Weinreb, G. A. Wong, L. A. Morse, R. S. Brown, M. E. Shapiro, R. L. Gingerich, L. K. Rosenlof, T. L. Pruett, D. K. Andersen, and J. B. Hanks. 1993. Sequential evaluation of islet cell responses to glucose in the transplanted pancreas in humans. $\mathrm{Am}$. J. Surg. 165:15-22.

27. Kryshak, E. J., P. C. Butler, C. Marsh, A. Miller, D. Barr, K. Polonsky, J. D. Perkins, and R. A. Rizza. 1990. Pattern of postprandial carbohydrate metabolism and effects of portal and peripheral insulin delivery. Diabetes. 39:142-48.

28. Homan, M., C. P. Nicholson, H. Katz, J. Perkins, M. Haymond, M. Jensen, P. Butler, and R. Rizza. 1991. Effects of chronic systemic insulin delivery on insulin action in dogs. Diabetologia. 34:702-708.

29. Reichard, G. A., Jr., N. F. Moury, N. J. Hochella, A. L. Patterson, and S Weinhouse. 1963. Quantitative estimation of the Cori cycle in the human. $J$. Biol. Chem. 238:495-501.

30. Herbert, V., K.-S. Lau, C. W. Gottlieb, et al. 1965. Coated charcoal immunoassay of insulin. J. Clin. Endocrinol. Metab. 25:1375-1384.

31. Radziuk, J., K. H. Norwich, and M. Vranic. 1978. Experimental validation of glucose turnover in non-steady state. Am. J. Physiol. 234:E84-E93.

32. Radziuk, J. 1986. Mathematical basis for the measurement of the rates of glucose appearance and synthesis in vivo. In Methods in Diabetes Research, vol. II. Clinical Methods. W. L. Clarke, J. Larner, and S. L. Pohl, editors. John Wiley \& Sons, Inc., New York. 91-106.

33. Vranic, M., J. Radziuk, and A. D. Cherrington. 1973. The role of glucagon and insulin in the glucoregulatory system, as assessed by tracer methods. In Regulation and Control in Physiological Systems. A. S. Iberall and A. C. Guyton, editors. International Federation of Automatic Control, distributed by the Instrument Society of America, Pittsburg, PA. 487-490.

34. Radziuk, J., K. H. Norwich, and M. Vranic. 1974. Measurement and validation of non-steady turnover rates with application to the insulin and glucose systems. Fed. Proc. 33:1855-1864.

35. Sherwin, R. S., K. J. Kramer, J. D. Tobin, P. A. Insel, J. E. Liljenquist, M. Berman, and R. Andres. 1974. A model of the kinetics of insulin in man. J. Clin. Invest. 53:1481-1492.

36. Bergman, R. N., L. S. Phillips, and C. Cobelli. 1981. Physiologic evaluation of factors controlling glucose tolerance in man. Measurement of insulin sensitivity and beta-cell sensitivity from the response to intravenous glucose. $J$. Clin. Invest. 68:1456-1458.

37. Montgomery, D. C. 1976. Design and Analysis of Experiments. John Wiley \& Sons, Inc., New York. 538 pp.

38. Cody, R. P., and J. K. Smith. 1991. Applied Statistics and the SAS Programming Language. Prentice Hall, Englewood Cliffs, NJ. 403 pp.

39. Norwich, N. H. 1973. Measuring rates of appearance in systems which are not in steady-state. Can. J. Physiol. Pharmacol. 51:91-101.

40. Cobelli, C., A. Mari, and E. Ferrannini. 1987. Non-steady state: error analysis of Steele's model and developments for glucose kinetics. Am. J. Physiol 252:E679-689.

41. Lickley, H. L. A., D. J. Chisholm, A. Rabinovitch, M. Wexler, and J. Dupre. 1975. Effects of portacaval anastomosis on glucose tolerance in the dog: Evidence of an interaction between the gut and the liver in oral glucose disposal. Metabolism. 24:1157-68.

42. Soeters, P. B., G. Weir, A. M. Ebeid, and J. E. Fischer. 1977. Insulin 
glucagon, portal systemic shunting, and hepatic failure in the dog. J. Surg. Res. 23:183-188.

43. Rosenlof, L. K., R. C. Earnhardt, T. L. Pruett, W. C. Stevenson, M. T. Douglas, G. C. Cornett, and J. B. Hanks. 1992. Pancreas transplantation: an initial experience with systemic and portal drainage of pancreatic allografts. $\mathrm{Am}$. Surg. 215:586-595.

44. Van Der Burg, M. P. M., H. G. Gooszen, O. R. Guicherit, J. B. M. J. Jansen, M. Frolich, F. A. Van Haastert, and C. B. H. W. Lamers. 1989. Contribution of partial pancreatectomy, systemic hormone delivery, and duct obliteration to glucose regulation in canine pancreas: importance in pancreas transplantation. Diabetes. 38:1082-89.

45. Kendall, D., D. Sutherland, J. Najarian, F. Goetz, and R. Robertson. 1990. Effects of hemipancreatectomy on insulin secretion and glucose tolerance in healthy humans. N. Engl. J. Med. 322:898-903.

46. Kergoat, M., M. Guerre-Millo, M. Lavau, and B. Portha. 1991. Increased insulin action in rats with mild insulin deficiency induced by neonatal streptozotocin. Am. J. Physiol. 260:E561-E567.
47. Field, J. B. 1972. Insulin extraction by the liver. In Endocrinology, vol. 1. Endocrine Pancreas. R. O. Grey and E. B. Astwood, editors. American Physiological Society, Washington D.C. 505-514.

48. Röjdmark, S., G. Bloom, M. C. Y. Chow, and J. B. Field. 1978. Hepatic extraction of exogenous insulin and glucagon in the dog. Endocrinology. 102:806-813.

49. Marangou, A. G., K. M. Weber, R. C. Boston, P. M. Aitken, J. C. P. Heggie, R. L. G. Kirsner, J. D. Best, and F. P. Alford. 1986. Metabolic consequences of prolonged hyperinsulinemia in humans: evidence for induction of insulin insensitivity. Diabetes. 35:1383-89.

50. DeFronzo, R. A., and E. Ferrannini. 1991. Insulin resistance: a multifaceted syndrome responsible for NIDDM, obesity, hypertension, dyslipidemia, and atherosclerotic cardiovascular disease. Diabetes Care. 14:173-194.

51. K. Falholt, R. Cutfield, R. Alejandro, A. Vølund, L. G. Heding, and D. H. Mintz. 1991. Influence of portal delivery of insulin on intracellular glucose and lipid metabolism. Metabolism. 40:122-126. 